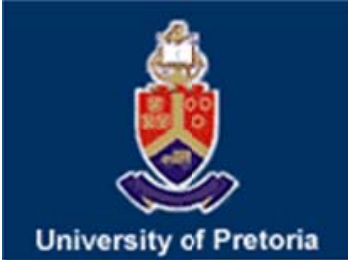

University of Pretoria Department of Economics Working Paper Series

\title{
Why must it always be so Real with Tax Evasion?
}

Rangan Gupta

University of Pretoria

Philton Makena

University of Pretoria

Working Paper: 2018-72

November 2018

Department of Economics

University of Pretoria

0002, Pretoria

South Africa

Tel: +27 124202413 


\title{
Why must it always be so Real with Tax Evasion?
}

\author{
Rangan Gupta* Philton Makena ${ }^{\dagger}$
}

November 8, 2018

\begin{abstract}
We provide an alternative theoretical explanation to the tax evasion-inflation relationship by endogenizing the discount factor in a standard overlapping generations endowment economy. When the discount factor is a positive function of non-productive public expenditure, then inflation is bound to increase seigniorage, leading to an increase in public expenditure. In consequence, old age consumption increases in importance such that tax evasion among young-age agents increases to enhance the interest income from savings.
\end{abstract}

\footnotetext{
* Department of Economics, University of Pretoria, Pretoria, 0002, South Africa.

${ }^{\dagger}$ To whom correspondence should be addressed. Department of Economics, University of Pretoria, Pretoria, 0002, South Africa. Email: philton.makena@gmail.com.
} 


\section{Introduction}

Traditionally, tax evasion is exogenous in Dynamic General Equilibrium (DGE) models when explaining seigniorage (Roubini and Sala-i Martin, 1995; Gupta et al., 2005). The realization that tax evasion is actually endogenous (behavioral decision) is made by Del Monte and Papagni (2001), Chen (2003), Gupta (2008), and Gupta and Ziramba (2009). Tax evasion depends on several real factors which include the tax rate, penalty rate, probability of being detected and corruption. However, empirical evidence consistently shows that tax evasion is positively-related to inflation as well (Schneider, 2007; Giles, 1999; Bittencourt et al., 2014).

There are several theoretical channels that link inflation and tax evasion. Gupta and Ziramba (2009) contend that inflation leads to higher tax evasion. The argument is that inflation compels government to increase transfers to the young-age and with more income, the young-age evade tax in order to save more and increase old-age consumption. Bittencourt et al. (2014) show that inflation leads to lower real return and hence higher tax evasion in order to save more and increase old-age consumption.

We provide an alternative theoretical explanation to the inflation-tax evasion nexus by endogenizing the discount factor in an overlapping generations (OLG) endowment-economy (see Gupta and Vermeulen (2010) for a detailed discussion of the endogenous discount factor). First, following Agénor (2010), the discount factor is a positive function of productive (health, education, infrastructure) public expenditure. Second, inflation increases seigniorage leading to an increase in public expenditure. This leads to an increase in the weight on the valuation of the future (old-age) and as such there will be higher incidences of tax evasion in order to save for old-age consumption. Third, since there is no old-age income in the OLG, the temptation to evade tax is high in order to increase interest income from savings for more consumption when old.

\section{Economic Setting}

The economy has three agents: two-period lived consumers, banks and an infinitely-lived government. Time is divided into discrete parts and is indexed by $t=1,2, \ldots$. At time $t$, there are two co-existing generations of young-age and old-age. At each time $t \geq 1, N$ people are born and at $t=1$, there exist $N$ people, the initial old, who live for only one period. The population, $N$, is normalized to 1 . There are four principal economic activities: (i) consumers receive a positive young-age endowment, $W$, from the government as a transfer, which they consume only when old. The young-age income is taxed by the government and part of the tax-liability is evaded, with evasion being determined endogenously in order to maximize utility. The rest of income is deposited into banks for consumption when old. Consumers can obtain loans from banks; (ii) Banks behave competitively but are subjected to cash reserve requirements administered by the government. Banks pool resources by collecting deposits from consumers and lending out funds to the same after meeting the mandatory cash reserve requirements; and (iv) Government meets its non-productive expenditure by taxing young-age income, generating seigniorage and setting a penalty for tax evasion. Two main government policy instruments are the money growth rate and the cash reserve requirement. Government balances its budget on a period-by-period basis. There is a continuum of each type of economic agent with unit mass.

\subsection{Consumers}

Young-age consumers receive an endowment, $W$, from government and are obliged to pay income tax, after which they save and invest the remainder by depositing it with banks and earn interest. 
Consumers can access bank loans at a cost, which they can contract and invest for a return. Consumption is only in period $t+1$. Young-age consumers face tax on income, $\tau$, set and imposed by the government. This tax-liability can be evaded successfully, with probability $\sigma$, or not, with a probability of $1-\sigma$. Consumers know ex-ante $1-\sigma$ and the penalty for attempting to evade $\operatorname{tax}, \theta$. However, they cannot avoid or insure against the risk of being caught.

Let $\beta_{t}$ be the fraction of income evaded in period $t$. If the young-age consumer is discovered of having evaded paying tax on a portion of income amounting to $\beta_{t} W$, then he must pay a penalty on undeclared income in period $t$, where $\theta>\tau$. To maximise his utility, the young-age consumer decides, upon receiving the endowment, consumption in period $t+1$, fraction of income to evade tax on, $\beta_{t}$ and bank deposits, $d_{t}$. After making his decisions, the ex-post tax state is revealed to him. If the tax state is "failure", the penalty is paid out of his savings. Formally, the consumer solves the following two-period problem:

$$
\max _{c_{y t}, \beta_{t}, d_{t}, c_{o t+1}^{1}, c_{o t+1}^{2}} U=u\left(c_{y t}\right)+\rho \sigma u\left(c_{o t+1}^{1}\right)+\rho(1-\sigma) u\left(c_{o t+1}^{2}\right)
$$

s.t:

$$
\begin{gathered}
p_{t} c_{y t}+p_{t} d_{t} \leq\left[\beta_{t}+\left(1-\beta_{t}\right)(1-\tau)\right] p_{t} W \\
p_{t+1}\left(c_{o t+1}^{1}\right) \leq\left(1+i_{d t+1}\right)\left[d_{t}-\delta W\right] p_{t} \\
p_{t+1}\left(c_{o t+1}^{2}\right) \leq\left(1+i_{d t+1}\right)\left[d_{t}-\theta \beta W-\delta W\right] p_{t} \\
0 \leq \beta_{t} \leq 1
\end{gathered}
$$

where $c_{y t}$ is real young-age consumption; $c_{o t+1}^{1}$ and $c_{o t+1}^{2}$ is real old-age consumption in tax states "success" and "failure", respectively. $\rho$ is the discount factor where $\rho$ is a positive function of government expenditure, $g$, and is expressed as $\rho=f_{1}(g / W)$ with $f_{1}^{\prime}()>0,. f_{1}^{\prime \prime}()<$.0 and $W=1 . \quad d_{t}$ are real deposits and $1+i_{d t+1}$ is gross nominal interest rate on bank deposits in period $t$; and $\delta$ is the transaction cost incurred to evade income tax. (2) is the period $t$ feasible budget constraint, (3) is period $t+1$ budget constraint in the tax state "success" and (4) is period $t+1$ budget constraint in the tax state "failure". The constraint in (5) is self-evident. In equilibrium, budget constraints (2) to (4) hold with equality since the depositor's utility function is increasing in consumption in each period. The solution to the consumer's problem yields the following first-order conditions (FOCs):

$$
\begin{gathered}
d_{t}: u^{\prime}\left(c_{y t}\right)=\rho\left(1+i_{d t+1}\right)\left[\sigma u^{\prime}\left(c_{o t+1}^{1}\right)+(1-\sigma) u^{\prime}\left(c_{o t+1}^{2}\right)\right] \\
\beta_{t}: \tau_{t} u^{\prime}\left(c_{y t}\right) \leq \rho \theta_{t}(1-\sigma)\left[1+i_{d t+1}\right] u^{\prime}\left(c_{o t+1}^{2}\right) \\
\beta_{t}: \tau_{t} u^{\prime}\left(c_{y t}\right)=\rho \theta_{t}(1-\sigma)\left[1+i_{d t+1}\right] u^{\prime}\left(c_{o t+1}^{2}\right) \\
\beta_{t}: \tau_{t} u^{\prime}\left(c_{y t}\right) \geq \rho \theta_{t}(1-\sigma)\left[1+i_{d t+1}\right] u^{\prime}\left(c_{o t+1}^{2}\right)
\end{gathered}
$$

for $\beta_{t}=0,0 \leq \beta_{t} \leq 1$ and $\beta_{t}=1$, respectively. The left-hand side of (7) represents the marginal benefit of tax evasion and the right-hand side the marginal cost of tax evasion. Implications of FOCs for the depositor are that when (a) marginal cost of tax evasion is greater than the marginal benefit, there is no incentive for tax evasion and hence $\beta_{t}=0$. (b) marginal benefit of tax evasion is greater than the marginal cost, there is no incentive to declare any income, and so $\beta_{t}=1$ (c) marginal benefit of tax evasion equals the marginal cost of tax evasion, there is a range of tenable tax evasion parameters, such that $0 \leq \beta_{t} \leq 1$. It is, however, required that $\tau_{t}>\theta_{t}(1-\sigma)$ for this interior solution to materialize, or that the set tax rate is higher than the potential penalty. 


\section{$2.2 \quad$ Banks}

There is a finite number of competitive banks, subjected to a mandatory cash reserve requirement, $\gamma_{t}$, administered by government. We assume that cost of operating a bank is zero and that bank deposits are one-period contracts. This guarantees that all banks levy the same nominal loan rate, $i_{l t}$, and guarantees the depositor the same nominal deposit rate, $i_{d t}$. Banks maximize profits by pooling deposits, choosing the level of loans to extend and the required cash reserves to hold. Banks receive interest income from loans to consumers and subsequently meet their deposit rate obligations to consumers. The balance sheet is constrained by the mandatory reserve requirement, and is represented by $\left(1-\gamma_{t}\right) D_{t}=L_{t}$. Banks attempt to:

$$
\max \prod_{B t}=i_{l t} L_{t}-i_{d t} D_{t}
$$

s.t:

$$
\begin{gathered}
M_{t}+L_{t} \leq D_{t} \\
M_{t} \geq \gamma_{t} D_{t}
\end{gathered}
$$

with $\prod_{B t}$ the bank's net profit function; $M_{t}$ are cash reserves held by banks to meet the reserve requirement and $L_{t}$ are nominal loans extended to consumers. (9) is the feasibility constraint and (10) is the reserve requirement constraint. Given that (9) and (10) binds, the solution to the bank's problem is:

$$
i_{l t}=\frac{i_{d t}}{1-\gamma_{t}}
$$

The cash reserve requirements induce a wedge between $i_{l t}$ and $i_{d t}$, as evident from (11). $M_{t}$ is rate-of-return dominated by loans, hence (9) will be binding as banks will hold just enough real money balances to satisfy the mandatory reserve requirements.

\subsection{Government}

An infinity-lived consolidated government purchases $g_{t}$ units of consumption goods, and government expenditure is assumed to be non-productive. Government consumption is financed by income tax, seigniorage and penalty income. The government's budget constraint is:

$$
g_{t}=\left(1-\beta_{t}\right) \tau_{t} W+\frac{M_{t}-M_{t-1}}{p_{t}}+(1-\sigma) \theta_{t} \beta_{t} W-(1-\sigma) v W
$$

$\left(1-\beta_{t}\right) \tau_{t} W$ is tax income, $\frac{M_{t}-M_{t-1}}{p_{t}}$ is seigniorage, $(1-\sigma) \theta_{t} \beta_{t} W$ is penalty income and $(1-\sigma) v W$ is cost of monitoring tax evasion. $M_{t}=\mu_{t} M_{t-1}$, and $\mu_{t}$ is the gross growth rate of money and following Del Monte and Papagni (2001), we assume that $(1-\sigma) v W$ is entirely offset by $(1-\sigma) \theta_{t} \beta_{t} W$, such that:

$$
g_{t}=\left(1-\beta_{t}\right) \tau_{t} W+\gamma_{t} d_{t}\left(1-\frac{1}{\mu_{t}}\right)
$$

\subsection{Equilibrium}

The competitive equilibrium for this economy is a sequence of prices $\left\{i_{l t} ; i_{d t} ; p_{t}\right\}_{t=0}^{\infty}$, allocations $\left\{c_{y t} ; c_{o t+1}^{1} ; c_{o t+1}^{2} ; \beta_{t} ; d_{t}\right\}_{t=0}^{\infty}$ and policy variables $\left\{\tau_{t} ; \gamma_{t} ; \theta_{t} ; \mu_{t} ; g_{t}\right\}_{t=0}^{\infty}$ such that:

- Given $\tau_{t}, \theta_{t}, i_{d t}$ and $W$, the depositor optimally chooses $\beta_{t}$ and $d_{t}$;

- Equilibrium money market condition, $m_{t}=\gamma_{t} d_{t}$ holds for all $t \geq 0$; 
- Loanable funds market equilibrium condition, $i_{l t}=\frac{i_{d t}}{\left(1-\gamma_{t}\right)}$ given the total supply of loans $l_{t}=\left(1-\gamma_{t}\right) d_{t}$, holds for all $t \geq 0$

- Banks maximise profits subject to $i_{l t}, i_{d t}$ and $\gamma_{t}$;

- Government budget constraint in (13) is balanced on a period-by-period basis; and

- $d_{t}, m_{t}, i_{l t}, i_{d t}$ and $p_{t}$ are positive for all periods.

\subsection{Model Solution}

The steady-state tax evasion parameter is

$$
\beta^{*}=\frac{\rho[\tau-\theta(1-\sigma)][1-\delta-\tau]}{(1+\rho)(\theta-\tau) \tau}
$$

and the steady-state size of deposits, in real terms, is

$$
d^{*}=\frac{[(1+\rho) \tau-\theta(1+\rho(1-\sigma))] \delta+[\theta \rho \sigma(1-\tau)]}{(1+\rho)(\theta-\tau)}
$$

while government's budget constraint in steady-state is

$$
g^{*}=\left(1-\beta^{*}\right) \tau+\gamma d^{*}\left[1-\frac{1}{\mu}\right]
$$

The relationship between inflation and tax evasion is illustrated in Figure 1 below.

Figure 1: Inflation and Tax Evasion

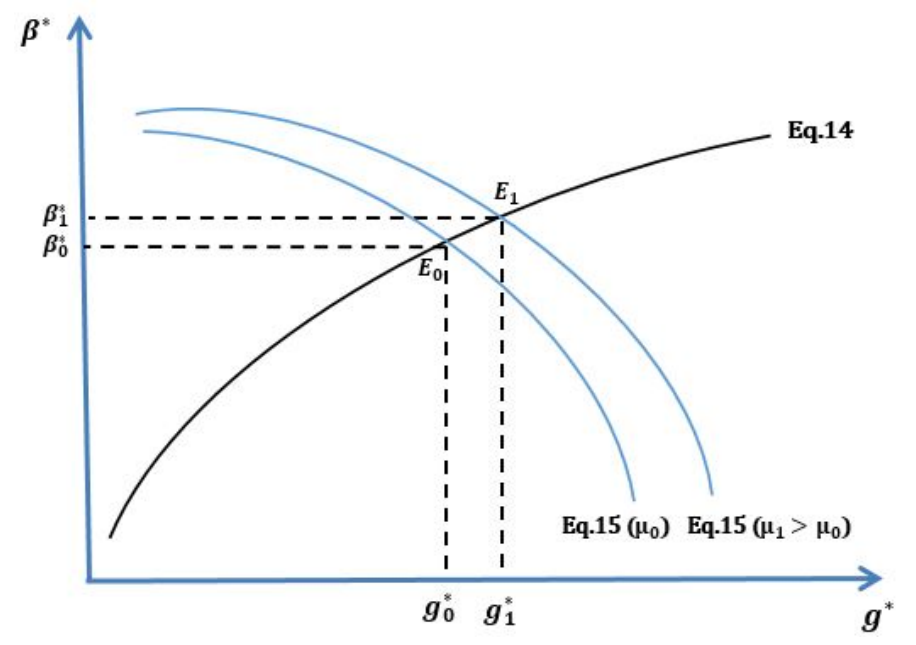

Inflation increases seigniorage and with it government expenditure, from $g_{0}^{*}$ to $g_{1}^{*}$. The discount factor, which is a positive function of $g$, increases and with it the temptation to evade tax. 


\section{Conclusion}

Empirical evidence says inflation increases tax evasion. There are a couple of existing theoretical explanations to this observation, based on income and interest rate channels. We develop a new theoretical model based on endogenous discounting. We show that when discounting is a positive function of non-productive public expenditure, inflation increases seigniorage and hence, the discount factor. In consequence, old-age consumption increases in importance such that tax evasion increases to enhance the interest income from savings. 


\section{References}

Agénor, P.-R. (2010). A theory of infrastructure-led development. Journal of Economic Dynamics and Control, 34(5):932-950.

Bittencourt, M., Gupta, R., and Stander, L. (2014). Tax evasion, financial development and inflation: Theory and empirical evidence. Journal of Banking \&3 Finance, 41:194-208.

Chen, B.-L. (2003). Tax evasion in a model of endogenous growth. Review of Economic Dynamics, 6(2):381-403.

Del Monte, A. and Papagni, E. (2001). Public expenditure, corruption, and economic growth: the case of italy. European journal of political economy, 17(1):1-16.

Giles, D. E. (1999). Measuring the hidden economy: Implications for econometric modelling. The Economic Journal, 109(456):370-380.

Gupta, R. (2008). Tax evasion and financial repression. Journal of Economics and Business, $60(6): 517-535$.

Gupta, R. et al. (2005). Costly state monitoring and reserve requirements. Annals of Economics and Finance, 6(2):263-288.

Gupta, R. and Vermeulen, C. (2010). Private and public health expenditures in an endogenous growth model with inflation targeting. Annals of Economics \&3 Finance, 11(1):139-153.

Gupta, R. and Ziramba, E. (2009). Tax evasion and financial repression: A reconsideration using endogenous growth models. Journal of Economic Studies, 36(6):660-674.

Roubini, N. and Sala-i Martin, X. (1995). A growth model of inflation, tax evasion, and financial repression. Journal of Monetary Economics, 2(35):275-301.

Schneider, F. (2007). Shadow economies and corruption all over the world: what do we really know? 


\section{A Appendix}

\section{A.1 Model Solution}

We take the competitive equilibrium conditions for our economic setting as outlined in Section 2.4 and impose a steady-state (no growth) on the economy. The government follows time-invariant policy rules and hence $\tau_{t}, \gamma_{t}, \theta_{t}$ and $\mu_{t}$ are all constant over time. Given these conditions, we yield a series of equations that we use to solve the steady state model.

The optimisation solution for the depositor yields two equations: one for $\beta^{*}$, the steady state tax evasion parameter and another for $d^{*}$, the steady state size of deposits, in real terms. Formally,

$$
\beta^{*}=\frac{\rho[\tau-\theta(1-\sigma)][1-\delta-\tau]}{(1+\rho)(\theta-\tau) \tau}
$$

and

$$
d^{*}=\frac{[(1+\rho) \tau-\theta(1+\rho(1-\sigma))] \delta+[\theta \rho \sigma(1-\tau)]}{(1+\rho)(\theta-\tau)}
$$

From (13), we have the the steady-state government's budget constraint represented by

$$
g^{*}=\left(1-\beta^{*}\right) \tau+\gamma d^{*}\left[1-\frac{1}{\mu}\right]
$$

\section{A.2 Derivation of the Relationship between Inflation and Tax Evasion}

The relationship between inflation and tax evasion, as depicted in Figure 1, can be derived from (A.1), (A.2) and (A.3). For (A.1), our focus is on the relationship between the tax evasion parameter, $\beta^{*}$ and the discount factor, $\rho$. First, we have that $\rho$ is a positive function of government expenditure, $g$, and is expressed as $\rho=f_{1}(g / W)$ with $f_{1}^{\prime}()>0,. f_{1}^{\prime \prime}()<$.0 and $W=1$. Thus, an increase in $g$ is associated with an increase in $\rho$, which entails that the young-age consumer now values old-age consumption more than before. Holding all the other parameters to the righthand-side of (A.1) constant and equal to $A$, such that $A=\frac{[\tau-\theta(1-\sigma)][1-\delta-\tau]}{(\theta-\tau) \tau}$ while $\rho$ is allowed to vary, we compute the first derivative of $\beta^{*}$ with respect to (w.r.t) $\rho$ and is

$$
\frac{\partial \beta^{*}}{\partial g^{*}}=A \frac{f_{1}^{\prime}(g)}{\left(1+f_{1}(g)\right)^{2}}
$$

From (A.4) we have that $\frac{\partial \beta^{*}}{\partial g^{*}}>0$ which confirms that (A.1) is an increasing function. An increase in $\rho$ emanating from an increase in $g$ is associated with an increase in $\beta^{*}$. We also compute the second derivative of $\beta^{*}$ with respect to (w.r.t) $\rho$ and is given by

$$
\frac{\partial^{2} \beta^{*}}{\partial^{2} g^{*}}=A \frac{f_{1}^{\prime \prime}(g)\left(1+f_{1}(g)\right)^{2}-2 f_{1}^{\prime}(g)\left(1+f_{1}(g)\right)}{\left(1+f_{1}(g)\right)^{4}}
$$

Given that $f_{1}^{\prime \prime}()<$.0 , then $\frac{\partial^{2} \beta^{*}}{\partial^{2} g^{*}}<0$, confirming that (A.1) is concave down, implying that $\frac{\partial \beta^{*}}{\partial g^{*}}$ is decreasing so that the slope of the tangent line to (A.1) is decreasing as $g$ increases. As depicted in Figure 1, (A.1) assumes an upward sloping, concave shape (with a positive slope that decreases as $g$ increases).

The relationship between $d^{*}$ and $\rho$ in (A.2) can be expressed as $d^{*}=f_{2}(\rho)$, where $\rho=f_{1}(g)$. As such, (A.5) can then be expressed as

$$
d^{*}=\frac{\left[\left(1+f_{1}(g)\right) \tau-\theta\left(1+f_{1}(g)(1-\sigma)\right)\right] \delta+\left[f_{1}(g) \theta \sigma(1-\tau)\right]}{\left(1+f_{1}(g)\right)(\theta-\tau)}
$$


If we consider (A.2), we take the first derivative of $d^{*}$ w.r.t $\rho$ and is expressed as

$$
\frac{\partial d^{*}}{\partial \rho}=\frac{\delta \tau-\theta[\delta-\sigma(\delta-\tau+1)]](1+\rho)-[\delta[\tau(1+\rho)-\theta]-\theta \rho[\delta-\sigma(\delta+1-\tau)]]}{(1+\rho)^{2}(\theta-\tau)}
$$

According to (A.7), $\frac{\partial d^{*}}{\partial \rho}>0$. We then take the second derivative of $d^{*}$ w.r.t $\rho$, and is expressed as:

$\frac{\partial^{2} d^{*}}{\partial^{2} \rho}=-\frac{[[\delta \tau-\theta[\delta-\sigma(\delta-\tau+1)]](1+\rho)-[\delta[\tau(1+\rho)-\theta]-\theta \rho[\delta-\sigma(\delta+1-\tau)]][2(1+\rho)(\theta-\tau)]}{(1+\rho)^{4}(\theta-\tau)^{2}}$

According to (A.8), $\frac{\partial^{2} d^{*}}{\partial^{2} \rho}<0$.

Given the the first and second derivatives of (A.2), we then focus on (A.3), which depicts the relationship between $\beta^{*}$ and $g$, inferred through the relationship between $d^{*}$ and $\rho$. This is so because the relationship between $\beta^{*}$ and $g$ is influenced by $d^{*}=f_{2}(\rho)$. We take the first derivative of $\beta^{*}$ w.r.t $g$ as follows:

$$
\begin{aligned}
& \partial g^{*}=-\tau \partial \beta^{*}+\gamma\left[1-\frac{1}{\mu}\right] f_{2}^{\prime}(\rho) \partial g^{*} \\
& -\tau \partial \beta^{*}=\left[1-\gamma\left(1-\frac{1}{\mu}\right) f_{2}^{\prime}(\rho)\right] \partial g^{*} \\
& \frac{\partial \beta^{*}}{\partial g^{*}}=-\frac{1}{\tau}\left[1-\gamma\left(1-\frac{1}{\mu}\right) f_{2}^{\prime}(\rho)\right]
\end{aligned}
$$

According to (A.9), the relationship between $\beta^{*}$ and $g^{*}$ is negative hence $\beta^{*}$ is a decreasing function of $g^{*}$, given that $\frac{\partial \beta^{*}}{\partial g^{*}}<0$. As such, an increase in $g$ is associated with a fall in $\beta$. While (A.3) is a decreasing function as confirmed by (A.9), its curvature is determined by the second derivative of (A.2) which is represented by (A.8) and is negative. That being the case, the second derivative of (A.9) becomes

$$
\frac{\partial^{2} \beta^{*}}{\partial^{2} g^{*}}=-\frac{1}{\tau}\left[1+\gamma\left(1-\frac{1}{\mu}\right) f_{2}^{\prime \prime}(\rho)\right]
$$

Since $\frac{\partial^{2} \beta^{*}}{\partial^{2} g^{*}}<0,\left(\right.$ A.3) is concave down implying that $\frac{\partial \beta^{*}}{\partial g^{*}}$ is decreasing so that the slope of the tangent line to (A.1) is decreasing as $g$ increases. Therefore, (A.3) is a decreasing function (downward sloping) and this is shown as (15) in Figure 1. 